\title{
Avaliação da capacitação espermática in vitro pela viabilidade e reação acrossômica*
}

\section{Evaluation of in vitro sperm capacitation through viability and acrosome reaction}

\author{
Wanderley Ferreira de Sá, ${ }^{\star \star},{ }^{\star * \star}$ Lopes, C.F.;** Luís Sérgio Almeida Camargo, ${ }^{\star *}$ Ademir de Moraes Ferreira, ${ }^{\star \star}$ \\ Alessandra de Almeida Vianna** João Henrique M. Viana, ${ }^{* \star}$ Luiz Altamiro Garcia Nogueira, ${ }^{* *}$
}

\begin{abstract}
Resumo
Avaliou-se a capacitação espermática in vitro de touros por meio da viabilidade espermática e indução da reação acrossômica. Utilizou-se sêmen congelado de touros da raça Gir, que após descongelado foi incubado in vitro com $0 \mathrm{ou} 10 \mu \mathrm{g} / \mathrm{ml}$ de heparina por quatro horas, para a capacitação, adicionando-se em seguida lisofosfatidilcolina por 15 minutos, para indução da reação acrossômica. Foram feitas lâminas para análise da viabilidade espermática (coradas com eosina/nigrosina) e reação acrossômica (coradas com naftol amarelo), antes e após o período de incubação. O tratamento com heparina proporcionou maior taxa de espermatozóides com reação acrossômica $(P<0,05)$, sem afetar a viabilidade espermática. Observou-se diferença entre touros quanto à viabilidade espermática e reação acrossômica antes e após a incubação com heparina + lisofosfatidilcolina $(P<0,05)$. O touro com maior reação acrossômica apresentou menor viabilidade espermática. Conclui-se, pelos resultados, que o sêmen antes de ser usado na fecundação in vitro, ou mesmo na monta natural ou inseminação, deva ter avaliada a capacitação espermática in vitro por meio da análise da taxa de viabilidade espermática e da taxa de reação acrossômica, por ambas apresentarem diferenças entre indivíduos.
\end{abstract}

Palavras-chave: fertilidade, sêmen, capacitação.

\begin{abstract}
The aim of this study was to evaluate the "in vitro" sperm capacitation of bulls through the sperm viability and acrosome reaction. Semen of Gir bulls was incubated at 0 and $10 \mu \mathrm{g} / \mathrm{ml}$ of heparin for four hours to capacitation. After then, lysophosphatidylcholine was added for $15 \mathrm{~min}$., to induce acrosome reaction. The spermatozoa viability and acrosome reaction were determined at the beginning and at the end of incubation time by a semen sample on a glass microscope slide, stained with eosin/nigrosin and yellow naphtol/erthyrosin $B$, respectively. The heparin treatment showed the highest rate of spermatozoa with acrosome reactions $(P<0,05)$, however it does no have effect on sperm viability. There was difference among bulls for spermatozoa viability and acrosome reactions before and after incubation time $(P<0,05)$. The bull that showed the highest acrosome reaction showed the lowest spermatozoa viability. Since both variable are important for the fertilization, it must be evaluated "in vitro" sperm capacitation of bulls by the analyses of sperm viability and acrosome reaction rate together, due the difference observed between bulls.
\end{abstract}

Keywords: fertility, semen, capacitation.

\section{Introdução}

Técnicas de produção in vitro de embriões bovinos podem ser utilizadas para a multiplicação de material genético, o que vem ocorrendo há pouco tempo em alguns países (Callesen et al., 1998). Nesse processo, a capacitação espermática é importante para a eficiência da fecundação, pois implica alterações fisiológicas que habilitam o espermatozóide a penetrar e fecundar o ovócito (Perez et al., 1997), proporcionando maior fertilidade. A descoberta da heparina como substância que capacita espermatozóides e induz reação acrossômica in vitro (Parrish et al., 1988), proporcionou grande avanço para a produção in vitro de embriões, além de ter facilitado o desenvolvimento de técnicas simples e úteis para avaliação da fertilidade de touros (Blottner et al., 1990; Whitfield e Parkinson, 1992), realizadas através de testes de reação acrossômica in vitro. Nessa avaliação, a capacitação espermática é induzida através da incubação do sêmen com heparina, e posteriormente avaliada a taxa de espermatozóides com reação acrossômica (RA). Como a RA é resultado da fusão das membranas interna e externa do acrossoma, provocando a

\footnotetext{
* Apoio financeiro: FAPEMIG.

** Embrapa Gado de Leite. Rua Eugênio do Nascimento, 610. Dom Bosco, Juiz de Fora, MG, CEP 36038-330.

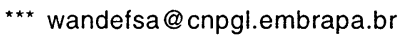

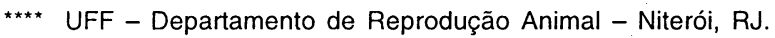


liberação de seu conteúdo, favorecendo a penetração espermática (Steinholt et al., 1991), faz-se necessário um agente indutor dessa reação, denominado lisofosfatidilcolina (LC) (Parrish et al., 1988), utilizado na concentração de $100 \mu \mathrm{g} / \mathrm{ml}$ por 15 minutos (Parrish et al., 1988; Thérien et al., 1995; McCauley et al., 1996), logo após o processo de capacitação. Segundo Whitfield e Parkinson (1992), $10 \mu \mathrm{g} / \mathrm{ml}$ de heparina induzem a capacitação e RA em espermatozóides bovinos.

A viabilidade espermática é outra variável importante para se obter maiores taxas de fertilização (Chandler et al., 1988). Tanto a capacitação como a viabilidade espermática são importantes para a penetração do espermatozóide no ovócito (Way et al., 1995). Portanto, a união desses dois fatores após a capacitação espermática são desejáveis para se aumentar a taxa de fertilidade de um touro.

O estudo visa avaliar a capacitação espermática in vitro com heparina em touros, através da indução da reação acrossômica in vitro e viabilidade espermática.

\section{Material e métodos}

Foram utilizados três touros da raça Gir, sendo que para cada touro foram usadas 12 palhetas de $0,5 \mathrm{ml}$ do sêmen congelado, pertencentes a uma mesma partida. O sêmen foi coletado e congelado em centrais de inseminação artificial, estocado e transportado em $\mathrm{N}_{2}$ líquido ao Laboratório de Reprodução da Embrapa Gado de Leite.

Três palhetas de sêmen de cada touro foram descongeladas em banho-maria a $37^{\circ} \mathrm{C}$, por 30 segundos, e imediatamente avaliadas quanto à motilidade e vigor, sendo depositadas em tubo de centrífuga e diluído com meio TALP Hepes para sêmen, numa proporção de 1:10 (Parrish et al.,1988) e centrifugado ( $300 \mathrm{~g}$ por 10 minutos). O sobrenadante foi desprezado e o sedimento ressuspendido no mesmo meio citado, na proporção de 1:1. A contagem da concentração espermática foi realizada em câmara de Neubauer, ajustando-se a concentração final para $20 \times 10^{6}$ espermatozóides/ $\mathrm{ml}$ em dois tubos, sendo um sem heparina (tratamento 1) e outro com 10 $\mu \mathrm{g} / \mathrm{ml}$ de heparina (tratamento 2).

Após a distribuição, os tubos foram levados para a estufa, onde permaneceram por quatro horas a $39^{\circ} \mathrm{C}$ e $95 \%$ de umidade. Ao final desse período, foram adicionados $100 \mu \mathrm{g} /$ $\mathrm{ml}$ de lisofosfatidilcolina (LC) e novamente incubados em estufa por mais 15 minutos.

A taxa de reação acrossômica (RA) foi avaliada através de esfregaços corados com a técnica do Naftol amarelo e Eritrosina B (Lenz et al.,1983). A leitura foi realizada três vezes, contando-se 100 células por lâmina, em aumento de de heparina 1000x (imersão) em microscópio de contraste de fase. Definiram-se como células com acrossoma íntegro, aquelas que apresentaram coloração avermelhada com ápice proeminente e bem definido, e células que sofreram reação acrossômica aquelas de coloração clara, sem o contorno acrossomal (Lenz et al., 1983). A viabilidade espermática foi avaliada através da técnica de coloração Eosina/Nigrosina (Dott e Foster, 1972), sem fixações posteriores. Foram adotados os mesmos procedimentos de leitura. Definiram-se como células viáveis aquelas que não coraram, apresentando apenas coloração de fundo na lâmina (acinzentado), e como células não viáveis aquelas que se coraram total ou parcialmente. As lâminas para reação acrossômica e viabilidade espermática foram confeccionadas no início (tempo zero hora) e fim (4h15min) da incubação.

Para cada touro foram realizados quatro testes, cada um com três palhetas de sêmen de uma mesma partida. As taxas analisadas foram de espermatozóides vivos e espermatozóides com reação acrossômica. Os dados foram avaliados por análise de variância, utilizando-se o SAS (Statistical Analisys System) (Sas, 1985), com experimento fatorial com delineamento em blocos casualizados. As variações entre as médias foram avaliadas pelo teste de comparação múltipla de Student-Newman-Keuls.

\section{Resultados e discussão}

Não houve diferença $(P>0,05)$ na porcentagem de espermatozóides vivos entre os tratamentos 1 (T1) e 2 (T2) no tempo 4h15 (Tabela 1), indicando que a heparina utilizada durante a capacitação, acrescida de LC, não afetou a viabilidade espermática, o que concorda com os resultados de Parrish et al. (1988).

A porcentagem de espermatozóides com reação acrossômica diferiu $(P<0,05)$ entre os tratamentos, sendo inferior no $T 1$, que

Tabela 1: Taxa de espermatozóides viáveis e com reação acrossômica antes e após capacitação espermática in vitro (período $0 \mathrm{~h}$ e $4 \mathrm{~h} 15$, respectivamente), para os tratamentos com 0 e $10 \mu \mathrm{g} / \mathrm{ml}$

\begin{tabular}{cccccc}
\hline Tratamento & $\begin{array}{c}\text { N.o de } \\
\text { observações }\end{array}$ & \multicolumn{2}{c}{ Viabilidade espermática (\%) } & \multicolumn{2}{c}{$\begin{array}{c}\text { Espermatozóides c/ } \\
\text { R.A } \mathrm{A}^{1}(\%)\end{array}$} \\
\hline $\begin{array}{c}\text { T1 }(0 \mu \mathrm{g} / \mathrm{ml} \text { de } \\
\text { heparina) }\end{array}$ & 12 & $59,33 \pm 5,79$ & $41,9 \pm 6,57^{\mathrm{a}}$ & $22,27 \pm 4,17$ & $52,19 \pm 7,71^{\mathrm{a}}$ \\
$\begin{array}{c}\mathrm{T} 2(10 \mu \mathrm{g} / \mathrm{ml} \text { de } \\
\text { heparina) }\end{array}$ & 12 & $59,33 \pm 5,79$ & $40,8 \pm 6,37^{\mathrm{a}}$ & $22,27 \pm 4,17$ & $60,64 \pm 5,79^{\mathrm{b}}$ \\
\hline
\end{tabular}

Médias com letras diferentes na mesma coluna diferem entre si $(P<0,05)$.

'R.A.: Espermatozóides com reação acrossômica

não continha heparina (Tabela 1). Essa diferença se deve à LC, que induz reação acrossômica preferencialmente em espermatozóides capacitados (Parrish et al., 1988). Entretanto, como os espermatozóides com degeneração celular também sofrem uma falsa reação acrossômica (Miller e Hunter, 1986), é necessário distinguir se essa diferença entre os tra- 
tamentos é devida à reação acrossômica em células vivas ou em células mortas. Como as taxas de espermatozóides viáveis entre os tratamentos foram semelhantes, estima-se que a diferença observada seja devida à reação acrossômica em espermatozóides vivos. Para Whitfield e Parkison (1992), a concentração de $10 \mu \mathrm{g} / \mathrm{ml}$ de heparina é suficiente para iniciar a capacitação espermática bovina. $O$ efeito da heparina na capacitação está na sua habilidade em preparar o espermatozóide para a reação acrossômica. A heparina exerce esse efeito através das proteínas com afinidade à heparina (HPB) presentes nos espermatozóides após a ejaculação (Bellin et al., 1994; Cox et al., 1995).

Verifica-se, portanto, que a concentração de heparina utilizada nesse experimento provocou a capacitação espermática in vitro dos touros testados, quando avaliada pelo teste de reação acrossômica, sem afetar a viabilidade do sêmen.

$\mathrm{Na}$ Tabela 2 observa-se que a porcentagem de espermatozóides vivos, no período de $0 \mathrm{~h}$ e ao final da incubação de $4 \mathrm{~h} 15$, diferiu entre os touros avaliados $(P<0,05)$, indicando uma variação individual na viabilidade espermática antes e após a incubação. Segundo Gibbons et al. (1994), existem diferenças no metabolismo das células espermáticas capazes de provocar efeitos diversos na viabilidade espermática para cada touro. Um espermatozóide necessita estar capacitado e vivo para fertilizar um ovócito (Way et al., 1995). A utilização de sêmen que se mantenha viável por mais tempo aumenta as chances de fecundação, permitindo maior exposição do ovócito a uma maior concentração de espermatozóides viáveis. Sendo assim, o sêmen que possuir maior viabilidade espermática durante e após a capacitação, provavelmente produzirá maior taxa de fecundação. Chandler et al. (1988) concluíram que a viabilidade do sêmen é essencial nos programas de inseminação artificial. O fato de haver diferença individuais entre touros quanto à viabilidade espermática mostra a necessidade de se realizar essa avaliação após o período de capacitação in vitro.

Tabela 2: Taxa de espermatozóides viáveis e com reação acrossômica após capacitação espermática in vitro (período oh e $4 \mathrm{~h} 15$, respectivamente), para os touros $\mathrm{A}, \mathrm{B}, \mathrm{C}$.

\begin{tabular}{|c|c|c|c|c|c|}
\hline \multirow{2}{*}{ Touro } & \multirow{2}{*}{$\begin{array}{c}\mathrm{N} .^{\circ} \text { de } \\
\text { observações }\end{array}$} & \multicolumn{2}{|c|}{ Viabilidade espermática (\%) } & \multicolumn{2}{|c|}{ Espermatozóides com R.A (\%) } \\
\hline & & $\mathrm{Oh}$ & $4 h 15$ & $\mathrm{On}$ & $4 h 15$ \\
\hline A & 4 & $56,33 \pm 5,7$ & $35,38 \pm 2,2^{a}$ & $25,08 \pm 1,28$ & $64,09 \pm 4,94^{a}$ \\
\hline B & 4 & $61,41 \pm 7,5$ & $40,22 \pm 2,8^{b}$ & $22,91 \pm 3,16$ & $61,59 \pm 8,27^{\mathrm{ab}}$ \\
\hline C & 4 & $60,25 \pm 3,78$ & $48,26 \pm 5,28^{c}$ & $18,33 \pm 5,04$ & $58,59 \pm 7,52^{b}$ \\
\hline
\end{tabular}

Médias com diferentes letras na mesma coluna diferem entre si $(P<0,001)$.

'R.A.: Espermatozóides com reação acrossômica

Observou-se diferença $(\mathrm{P}<0,05)$ entre touros quanto à taxa de espermatozóides com reação acrossômica após o período 0 $\mathrm{h}$ e de $4 \mathrm{~h} 15$ (Tabela 2). Nos dois períodos avaliados, o touro A apresentou a maior taxa de reação acrossômica e menor taxa de espermatozóides vivos após a capacitação in vitro.
Este aumento na taxa de reação acrossômica pode ser devido ao maior número de espermatozóides mortos desse touro (falsa reação acrossômica), mostrando-se necessária a avaliação das duas variáveis após a capacitação espermática in vitro, visto que para a fecundação é de interesse um sêmen com alta taxa de espermatozóides com reação acrossômica e viabilidade. Considerando estes fatos, o touro C apresenta melhor resultado após a capacitação espermática in vitro, pela maior taxa de espermatozóides viáveis do que os outros touros, e taxa de reação acrossômica às $4 \mathrm{~h} 15$ semelhante ao touro $B$, apesar de ser inferior ao touro $A$ (Tabela 2). O touro $A$, apesar de ter uma taxa de espermatozóides com reação acrossômica superior, apresenta uma viabilidade menor, devido à baixa taxa de espermatozóides viáveis.

A taxa de reação acrossômica à $0 \mathrm{~h}$, conforme esperado, foi baixa, uma vez que os espermatozóides não haviam entrado em contato com nenhum indutor de reação acrossômica. Essa taxa aumenta após a incubação com o agente capacitador (heparina) e indutor de reação. A diferença entre oh e 4 h15 permite avaliar a taxa dos espermatozóides que sofreram reação acrossômica provocada pela incubação com heparina e LC. Calculando a diferença na taxa de reação acrossômica entre 0 h e 4 h15 para cada touro, observa-se na Tabela 2 que os touros $A$ e $C$ apresentam valores de reação acrossômica semelhantes. Desse modo, as taxas de reação acrossômica analisadas são iguais e, como a viabilidade espermática é maior para o touro $\mathrm{C}$, este tende a apresentar melhor resultado na capacitação espermática com heparina.

Diversos autores, avaliando touros da raça Holandesa, encontraram uma correlação alta entre a taxa de reação acrossômica após a incubação e a taxa de não retorno a campo (Lenz et al., 1988; Whitfield e Parkinson, 1992). Entretanto, a taxa de espermatozóides viáveis após o período de incubação não tem sido avaliada. Whitfield e Parkinson (1992) encontraram correlação alta entre a taxa de reação acrossômica e não-retorno aos 90 dias, e correlação baixa entre a reação acrossômica e porcentagem de espermatozóides móveis após o descongelamento do sêmen. Todavia, não avaliaram a taxa de espermatozóides viáveis após a incubação para a capacitação espermática. Como citado anteriormente, a viabilidade espermática é dependente do metabolismo dessas células (Gibbons et al., 1994), provocando diferentes efeitos em cada touro. Por isso, espera-se que a viabilidade espermática seja diferente entre touros, após a capacitação in vitro, prejudicando a capacidade de fecundação do sêmen com menor viabilidade.

Observou-se neste estudo que a capacitação espermática in vitro em touros é aumentada quando se utiliza heparina. Entretanto, existe diferença entre touros quanto ao comportamento 
do sêmen frente à capacitação espermática in vitro, quando avaliados pela viabilidade espermática ou reação acrossômica.

\section{Conclusões}

A heparina, na concentração de $10 \mu \mathrm{g} / \mathrm{ml}$, induz à capacitação espermática.

\section{Referências}

BELLIN M.E., HAWKINS H.E., AX R.L. Fertility of range beef bulls grouped according to presence or absence of heparin-binding proteins in sperm membranes and seminal fluid. Journal Animal Science, v.1, n.7, p. 2441-2448, 1994.

BLOTTNER, S., NEHRING, H., TORNER, H. Individual differences in capacitation of bull spermatozoa by heparin in vitro:relationship to fertility. Theriogenology, v. 34, p. 619-628, 1990.

CALLESEN, H., GREVE, T., AVERY, B. Embryo Technology in Cattle: Brief Review. Acta Agric.Scand.(Suppl.), v. 29, p.19-29, 1998.

CHANDLER, J.E., PAINTER, C.L., ADKINSON, R.W., MEMON, M.A., HOYT, P.G. Semen quality characteristics of dairy goats. Journal Dairy Science, v. 71, p. 1638-1646, 1988.

COXJ.F., SARAVIA F., BRIONESM., SANTA MARIAA. Dose-dependent effect of heparin on fertilizing ability of goat spermatozoa. Theriogenology, v. 44, p. 451-460, 1995.

DOTT, H. M., FOSTER, G. C. A technique for studying the morphology of mammalian spermatozoa which are eosinophilic in a differential "lifedead" stain. Journal Reproduction and Fertility, v. 29, p. 443-445, 1972. GIBBONS, J.R., BEAL, W.E., KRISHEER, R.L., FABER, E.G., PEARSON, R.E., GWZDAUSKAS, F.C. Effects on once-versus twice weekly transvaginal follicular aspiration on bovine oocytes recovery and embryo development. Theriogenology, v. 42, p. 405-419, 1994.

LENZ, R.W., BALL, G.D., LOHOSE, J.K., FIRST, N.L., AX, R.L. Chondroitingsulfate facilitates on acrosome reaction in bovine spematozoa as evidenced by light microscopy, electron microscopy and in vitro fertilization. Biology Reproduction,v. 28, p. 683-690, 1983.

LENZ, R.W., MARTIN, J.L.; BELLIN, M.E. et al. Predicting fertility of dairy bulls by inducing acrosome reactions in sperms with chondroitin sulfates. Journal Dairy Science, v. 71, p. 1073-1077, 1988.
As análises da reação acrossômica e da viabilidade dos espermatozóides devem ser usados para avaliação da capacitação espermática in vitro entre diferentes touros, tendo em vista sua importância para a fecundação, além das diferenças entre indivíduos.

MILLERD.J., HUNTER A.G. Effect of osmolality and glycosaminoglycans on motility, capacitation, acrosome reaction, and in vitrofertilizability of bovine ejaculated spermatozoa. Journal Dairy Science, v. 69, p. 29152924, 1986.

MCCAULEY, T.C., BELLIN, M.E., AX, R.L. Localization of heparin-binding protein to distinct regions of bovine sperm. Journal Animal Science, v. 74, p. 429-437, 1996.

PARRISH, J. J., SUSKO-PARRISH, J., WINER, M. A., FIRST, N. L. Capacitation of bovine sperm by heparin. Biology Reproduction, v. 38 p. 1171-1180, 1988.

PÉREZL.J., VALCÁRCEL A., DE LAS HERAS M.A., et al. The storage of pure ram semen at room temperature results in capacitation of a subpopulation of spermatozoa. Theriogenology, v.47, p.549-558, 1997.

STATISTICAL ANALISYS SYSTEM (SAS), Institute SAS User's Guide: Statistics, 5. ed. Cary, 1985. 956 p.

STEINHOLTH.C., CHANDLER J.E., TIRADO V. Evaluating acrosome reaction steps with brightfield and differential interference contrast microscopy techniques. Journal Dairy Science, v. 74, p. 3822-3826, 1991.

THÉRIEN, I., BLEAU, G., MANJUNATH, P. Phosphatidylcholine-binding proteins of bovine seminal plasma modulate capacitation of spermatozoa by heparin. Biology Reproduction, v. 52, p. 1372-1379, 1995.

WAY, A.L.; HENAULT, M.A.; KILLIAN, G.J. Comparison of four staining methods for evaluating acrosome status and viability of ejaculated and cauda epididymal bull spermatozoa. Theriogenology, v. 43, p. 13011316, 1995.

WHITFIELD, C. H., PARKISON, T. J..Relationship between fertility of bovine semen and in vitro induction of acrosome reactions by heparin. Theriogenology, v. 38, p.11-20, 1992. 